Article

\title{
Research on the Gradual Process of the Metallization Structures and Mechanical Properties of Wood Veneer
}

\author{
Jingkui Li, Ruoying Wang, He Tian, Yanan Wang and Dawei Qi * \\ College of Science, Northeast Forestry University, Harbin 150040, China; li_jing_kui@nefu.edu.cn (J.L.); \\ worry@nefu.edu.cn (R.W.); tianhe@nefu.edu.cn (H.T.); wang_ya_nan@nefu.edu.cn (Y.W.) \\ * Correspondence: qidw9806@nefu.edu.cn
}

Received: 1 October 2018; Accepted: 25 October 2018; Published: 26 October 2018

\begin{abstract}
In order to improve the mechanical properties of the wood surface and explore the mechanical effect of wood veneer surface metallization, the 31-year-old Pinus sylvestris is taken as the research object and $\mathrm{Cu}$ is deposited on the wood surface by magnetron sputtering to achieve wood veneer metallization. Based on X-ray diffraction (XRD) and nanoindentation, a research on the gradual process of the structures and mechanical properties of wood veneer metallization was carried out. The results indicate that wood veneer metallization does not affect the crystallization zone of wood, there are still wood cellulose characteristic peaks and the crystalline structure of the wood cellulose is not damaged; the thickness of the copper thin film increases with the increase of the deposition time, the cellulose characteristic peak strength gradually decrease, and the relative crystallinity also decreases; the characteristic diffraction peaks of $\mathrm{Cu}(111), \mathrm{Cu}(200)$, and $\mathrm{Cu}(220)$ appear near the diffraction angle $2 \theta$ which is equal to $43.3^{\circ}, 50.4^{\circ}$, and $74.1^{\circ}$, and the diffraction peak intensity increases with increase of deposition time, the copper film of the metal wood veneer crystallizes well; the load-displacement of wood veneer decreases significantly with the increase of deposition time, while the moduli of elasticity and hardness increase rapidly. The load-displacement of the samples which were coated for 15 min decreased by $80 \%$, while the moduli of elasticity and hardness of these samples increased by 24.1 times and 17.3 times, respectively. From the results of Scanning Electron Microscope (SEM) measurement of the metallization of wood veneer, it can be seen that the uniform and continuous copper film can be formed on the wood veneer surface by using the magnetron sputtering method. This paper provides a basis for wood veneer surface metallization, which is of great significance for the functional improvement of wood, the expansion of wood application fields, and the enhancement of added value.
\end{abstract}

Keywords: wood metallization; film structure; nanoindentation; modulus of elasticity; hardness

\section{Introduction}

Wood is a kind of natural organic polymer material, its hardness and modulus of elasticity are much smaller than metal, and problems exist such as small density, low intensity, easy deformation and cracking, decay, moth, and easy combustion [1]. In recent years, composite wood and metal material to give wood metal properties is one of the research direction of new multifunctional materials, which can also improve wood intensity, adjust wood surface color, enhance wood surface hardness, increase wood abrasion resistance, and so on [2].

The effects of electroless nickel plating on the electrical conductivity and electromagnetic shielding properties of electroless nickel plating veneer were studied in Japan in the 1990s [3]; Zhao Guangjie et al. conducted electroless plating research on wood and studied its conductivity and electromagnetic shielding properties [3,4]; Sun Lili used electroless plating method to prepare electromagnetic shielding materials on birch veneers, and tested surface resistivity and electromagnetic 
shielding effectiveness [5]; Wang Li et al. obtained a corrosion-resistant wood-based electromagnetic shielding material for the study of electroless nickel-plated ternary alloys on wood surface [6]. The electroless copper-nickel plating on wood surface and its microstructure and properties were studied by Jia Jin et al. and the electrical conductivity and wettability were discussed [7]. "The Key Technology of Material Improvement and Functionalization based on Wood Cell Modification", which was completed by academician Li Jian, won the second prize of National Science and Technology Progress in 2017, and the chemical plating method on the wood surface developed to an unprecedented stage. The electroless plating treatment of wood electromagnetic shielding material not only keeps the excellent properties of wood, but also improves the electrical conductivity, thermal conductivity, and electromagnetic shielding performance of wood. The appearance of this material paves the way for the development of wood increment and widens the field of processing and application of electromagnetic shielding materials [8].

However, most of the wood electroless copper platings choose formaldehyde as a reducing agent: the toxicity of formaldehyde causes serious harm to human body and environment. In addition, the method of electroless plating to prepare thin films is a liquid phase method. It is necessary to place the wood substrate in the plating solution for a long time to achieve the wood surface coating. This is very harsh to the chemical plating bath ratio, reaction temperature and time, and causes great damage to the natural properties of the wood, and some problems exist in the chemical plating of wood [9].

Magnetron sputtering is a kind of physical vapor deposition, which can be used to prepare metal, semiconductor, insulator, and other multifilm materials. It has the advantages of simple equipment, easy control, large coating area, and strong adhesion. At the same time, green production technologies, which do not pollute via waste water and meet the relevant environmental protection standards, have been widely used in the preparation of various nanomaterial thin films in recent years [10]. Chang Delong et al. attempted to prepare a metallized film by magnetron sputtering on the surface of plywood, and studied its weather resistance and electromagnetic shielding effectiveness [11].

Nanoindentation can directly achieve many mechanical properties of film materials without the aid of separation membrane and substrate, such as modulus of elasticity, hardness, and so on. It works by measuring the load on the nanoprobes and the depth of the pressed sample surface to obtain abundant mechanical information such as hardness, modulus of elasticity, load-displacement curve, and creep properties [12-14]. In recent years, this technology has been rapidly expanded into material science [15-17]. Gindl W. et al. measured the mechanical properties of the spruce cell wall with nanoindentation [18]. Gindl W. et al. discussed the significance of measuring the modulus of elasticity of the cell wall of wood with nanoindentation [19]. Jiang zehui et al. [20] used nanoindentation to test the modulus and hardness of the cell wall of a plantation of Chinese fir. However, few studies have been reported on the metallization of the wood veneer surface by magnetron sputtering and the gradual process of the metallization structures and mechanical properties of wood veneer using X-ray diffraction (XRD) and nanoindentation. So, we took 31-year-old Pinus sylvestris as the research object and achieved wood veneer metallization by magnetron sputtering; it modified the wood interface and changed the wood microstructure. Then, we characterized the metallization structure of wood veneer by XRD and studied the changes of the mechanical properties of the coated wood surface such as hardness and modulus of elasticity at the nanoscale. The way to prepare the metallization film and the gradual process of determining the structure and mechanical properties of wood veneer were revealed and explored, this paper provides a basis for the research and application of metallization on the wood veneer surface.

\section{Materials and Methods}

\subsection{The Experimental Materials}

In this experiment, the 31-year-old Pinus sylvestrisvar.mongolicaLitv. veneer was used as the material, and the core material was selected. The size of the veneer was about $1.5 \mathrm{~cm} \times 1.5 \mathrm{~cm} \times$ 
$0.5 \mathrm{~mm}$. The other materials are $99.99 \%$ copper target, melamine formaldehyde resin, $\mathrm{KH}-560$ silane coupling agent, anhydrous ethanol, dilute formic acid, acetone, distilled water, and sandpaper.

\subsection{Pretreatment of Wood Veneer}

The wood veneer sample was polished with 600, 800, 1000, 1500, and 2000 mesh abrasive paper from thickness to fineness, and the wood chip on the surface was cleaned for use with a blower. Taking distilled water as the solution, $\mathrm{MF}_{2}$ sealing agent solution (first adding the melamine-formaldehyde resin with a mass fraction of 50\%, and then adding the KH-560 silane coupling agent with a mass fraction of $1 \%$ to the solution) was prepared, and the solution was dissolved by stirring to form a uniform milky white paste liquid. We then applied the solution of $\mathrm{MF}_{2}$ sealing agent evenly on the polished wood veneer and let it dry naturally.

\subsection{Wood Veneer Metallization}

The preparation of the copper film on wood veneer surface was performed on a JGP450 multitarget magnetron sputtering device (SKY Technology Development Co., Ltd., Shenyang, China). The sputtering target material for the copper target had purity of $99.99 \%$. On the dc sputtering cathode, the substrate was used for the pretreatment of the wood veneer, then, we installed the treated wood veneer on the sample rack in the vacuum chamber. The vacuum of the background reached $8.0 \times 10^{-4}$ Pa bump argon into the vacuum chamber. The argon gas flow was fixed at $20 \mathrm{sccm}$, sputtering pressure was $5.0 \mathrm{~Pa}$, and the sputtering power was $100 \mathrm{~W}$. The thickness of the copper film grown on the wood veneer surface was controlled by changing the deposition time.

\subsection{Test of Modulus of Elasticity and Hardness}

In this experiment, Nano Indentert-XP nanoindenter manufactured by Mechanical Testing \& Simulation (MTS) of the United States was used to test the hardness and modulus of elasticity of the film metallized on the veneer surface. The test results were obtained by calculating the curve of loading and the penetration depth. There was no need to observe the indentation area through the microscope. The experiment used a diamond Berkovich tip with tip radius of curvature is less than $100 \mathrm{~nm}$, load resolution of $50 \mathrm{nN}$, displacement resolution less than $0.01 \mathrm{~nm}$, loading and unloading mode of quasistatic and constant rate, maximum load of $0.5 \mathrm{mN}$, loading time of $5 \mathrm{~s}$, dwelling time of 1 s, Poisson ratio was $0.18,5$ points for each sample indentation, and the whole test process was completed by computer control.

According to the O\&P method of Oliver et al. [21], the hardness of nano indentation $H$ :

$$
H=\frac{P_{\max }}{A\left(h_{c}\right)}
$$

where $P_{\max }$ is the load on the tip at the maximum indentation depth, $A$ is the contact area (projected area) of the load at the maximum indentation depth, and $h_{\mathcal{C}}$ is the contact depth of the tip.

The modulus of elasticity of the sample $E$ :

$$
E=\left(1-v^{2}\right)\left(\frac{1}{E_{r}}-\frac{1-v_{i}^{2}}{E_{i}}\right)^{-1}
$$

where $E_{r}$ is the corresponding modulus of the recombination, $E_{i}$ is the modulus of elasticity of the tip, $v$ is the Poisson's ratio of the sample, and $v_{i}$ is the Poisson's ratio of the tip.

\subsection{Characterization of Wood Veneer Metallization Structure}

In order to study the metallization structure of wood veneers and the crystallinity of wood cellulose at different sputtering times, the wood veneers after magnetron sputtering were characterized by XRD-6100 produced by the Shimadzu Corporation of Japan. The condition is CuK $\alpha$ copper target 
radiation $(\lambda=0.154 \mathrm{~nm})$. The radiant tube voltage is $40 \mathrm{kV}$, and the radiant tube current is $30 \mathrm{~mA}$. The scanning range is $2 \theta=10-80^{\circ}$, the film sample has a fixed tilt angle of $\theta=4^{\circ}$, step size of $0.02^{\circ}$, and scanning speed of $2^{\circ} / \mathrm{min}$.

The crystallinity of wood is measured by the crystallinity index, which is calculated by the percentage of the crystal part in the whole sample, and the change of the crystallinity of wood cellulose is calculated by the empirical method such as Segal et al. [22-24], as shown in Figure 1, the relative crystallinity of wood cellulose $C_{r} I \%$ :

$$
C_{r} I \%=\frac{I_{002}-I_{a m}}{I_{002}} \times 100 \%
$$

where $C_{r} I \%$ is relative crystallinity, $I_{002}$ is the maximum intensity of (002) lattice diffraction Angle (near $2 \theta=22^{\circ}$ ), and $I_{a m}$ is the diffraction intensity of amorphous region (near $2 \theta=18^{\circ}$ ).

\section{Results and Analysis}

\subsection{Analyze Wood Veneer Metallization Structure with XRD}

The structural changes in wood veneer metallization are shown in Figure 1. The unsputtered raw wood veneer samples and the metallized samples were analyzed and compared by XRD patterns. The copper plating times were $50 \mathrm{~s}, 150 \mathrm{~s}, 10 \mathrm{~min}$, and $15 \mathrm{~min}$, respectively. It can be seen that there are characteristic peaks of three crystal faces $(101,002$, and 040$)$ of cellulose in wood near $17.0^{\circ}, 22.5^{\circ}$ and $35.0^{\circ}$. The results show that the metallization of wood veneers by magnetron sputtering has no effect on the crystallization zone of wood, and the crystal structure of wood cellulose after wood metallization has not been destroyed.

However, the strength of the three crystal surface characteristic peaks gradually decreased with the increase of deposition time, and the relative strength of diffraction peak $(101,002)$ that mainly affected the wood crystallinity decreased most significantly with sputtering time. The relative strength of the crystal face (002) diffraction peak decreased by $28.1 \%$ when the deposition time was $50 \mathrm{~s}, 34.1 \%$ for $150 \mathrm{~s}, 41 \%$ for $10 \mathrm{~min}$, and more than $50 \%$ for $15 \mathrm{~min}$. One reason for the decrease of intensity of diffraction peak is that the thickness of copper film increases with the increase of coating time, and that the X-ray radiation depth in wood decreases. Another reason is that the growth of copper thin films will absorb and reflect the diffraction line of wood, and also cause the wood cellulose characteristic peak strength to decline.

Relative crystallinity was calculated according to Formula 3 for calculating the crystallinity of wood cellulose. The crystallinity of the sample decreased by $5.3 \%$ when the sputtering time was $50 \mathrm{~s}, 1.7 \%$ for $150 \mathrm{~s}, 4.9 \%$ for $10 \mathrm{~min}$, and $10.8 \%$ for $15 \mathrm{~min}$. Compare the copper plating samples and the original samples, the crystallinity of the coating samples decreased and the change law was not obvious. However, sputtering over $15 \mathrm{~min}$ showed the greatest decrease in relative crystallinity. The cellulose molecular chains of the wood crystalline region are arranged tightly and orderly, the sealing agent and sputtering of copper atoms cannot enter the crystalline region, while the structure in the amorphous zone is loose. In the process of the wood veneer coating treatment, some of the copper atoms of sealing agent and sputtering enter into the nanovoid of wood and infiltrate into the amorphous area of the wood cell wall. With the increase in thickness of copper film, the quality of the amorphous area increases and the crystallinity of wood cellulose decreases [25].

The XRD pattern of the copper film metallized by wood veneer is shown in Figure 1. As can be seen from Figure 1, the film thickness increases with the increase in coating time. The diffraction peaks of $\mathrm{Cu}(111), \mathrm{Cu}(200)$, and $\mathrm{Cu}(220)$ appear near $2 \theta, 43.3^{\circ}, 50.4^{\circ}$, and $74.1^{\circ}$, and the diffraction peak intensity increases with the increase of coating time. There was no obvious characteristic diffraction peak of copper when the sputtering time was $50 \mathrm{~s}$, indicating that the copper film was microcrystalline or amorphous. Diffraction peak of $\mathrm{Cu}(111)$ appeared at sputtering time of $150 \mathrm{~s}$. Diffraction peaks of $\mathrm{Cu}$ (111), $\mathrm{Cu}$ (200), and $\mathrm{Cu}(220)$ have appeared when sputtering time is $10 \mathrm{~min}$ and $15 \mathrm{~min}$, reflecting 
a good crystallization state. In addition, it can be seen that with the increase of sputtering time, the characteristics of diffraction peak intensity of copper gradually strengthened. As the growth of copper film has a selective orientation, the change of $\mathrm{Cu}$ (111) diffraction peak is the most obvious. The reason is that copper is the material of face-centered cubic structure, and its atomic surface density on $\mathrm{Cu}$ (111) is the largest, the surface energy of the crystal surface with higher atomic surface density is less, which is beneficial to the growth of crystal surface.

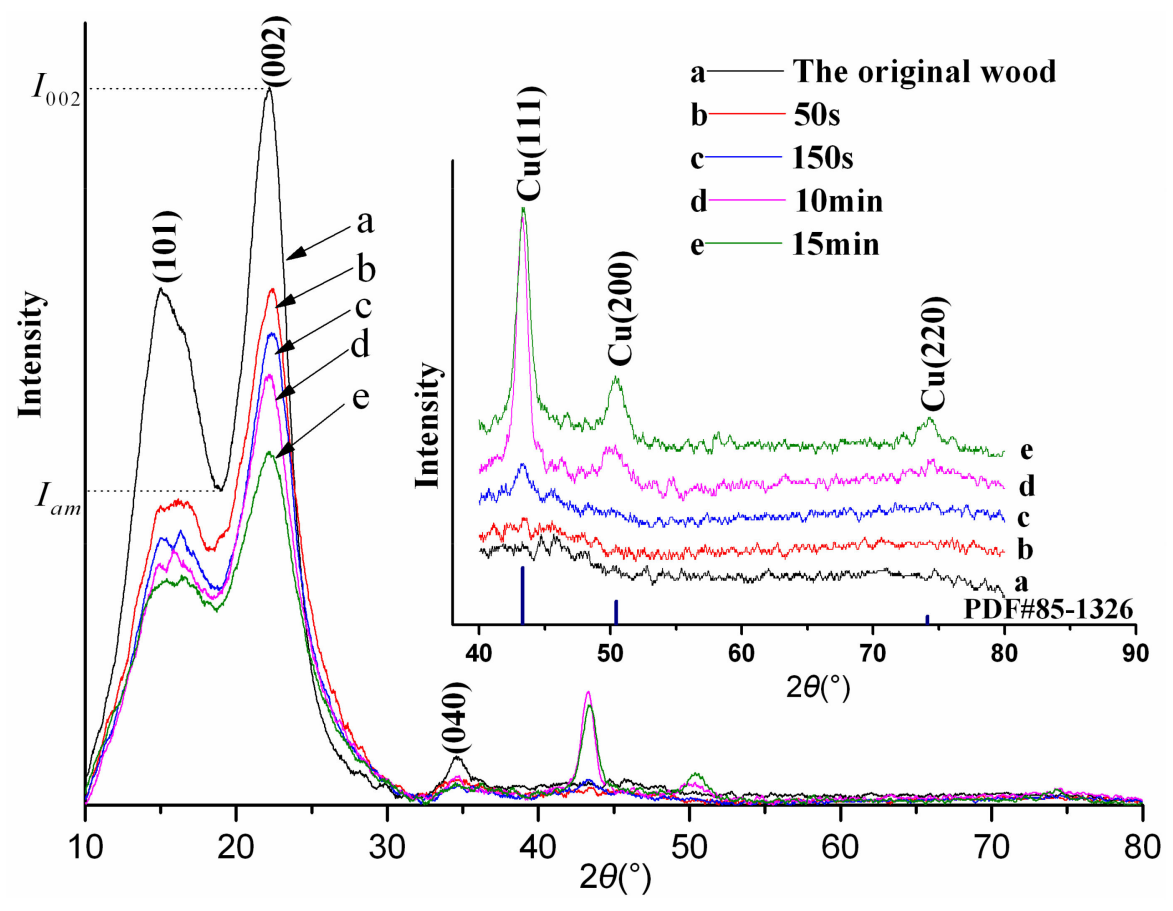

Figure 1. X-ray diffraction (XRD) of wood veneer metallization.

\subsection{Effect of Wood Veneer Metallization on Load-Compaction Depth}

The load-compaction depth curve of wood veneer before and after metallization is shown in Figure 2. During the loading process, elastic deformation and plastic deformation occurred on the sample, resulting in the nonlinearity of the loading curve. The unloading curve reflects the elastic recovery process of the sample. The whole process consists of loading, holding, and unloading phases. It can be seen that the load-compression depth curve of the metallized wood veneer sample treated with magnetron sputtering on the surface is significantly shifted to the left compared with the original wood sample, the sample with sputtering time of $50 \mathrm{~s}$ is the smallest and the sample with sputtering time of $15 \mathrm{~min}$ is the largest. From the loading curve, the maximum load of the quasistatic constant rate loading and unloading mode was $0.5 \mathrm{mN}$ and the loading time was $5 \mathrm{~s}$. The loading displacement of the original wood was $684 \mathrm{~nm}$, and of the sample coating $50 \mathrm{~s}$ was $210.9 \mathrm{~nm}, 139.1 \mathrm{~nm}$ for $150 \mathrm{~s}$, $126.9 \mathrm{~nm}$ for $10 \mathrm{~min}$, and $107.7 \mathrm{~nm}$ for $15 \mathrm{~min}$. The loading displacement decreased by more than $80 \%$. Therefore, when the thickness of the sputtering film is small, the load displacement of the sample decreases continuously with the increase of deposition time. The load-compaction depth curve of the sample reflects the change in load displacement of the metallized wood veneer with the increase of deposition time. As the coating time increases, the influence of the wood base effect and the porous structure of wood on the load-compaction depth curve become smaller, indicating that the measurement stability and repeatability become better. 


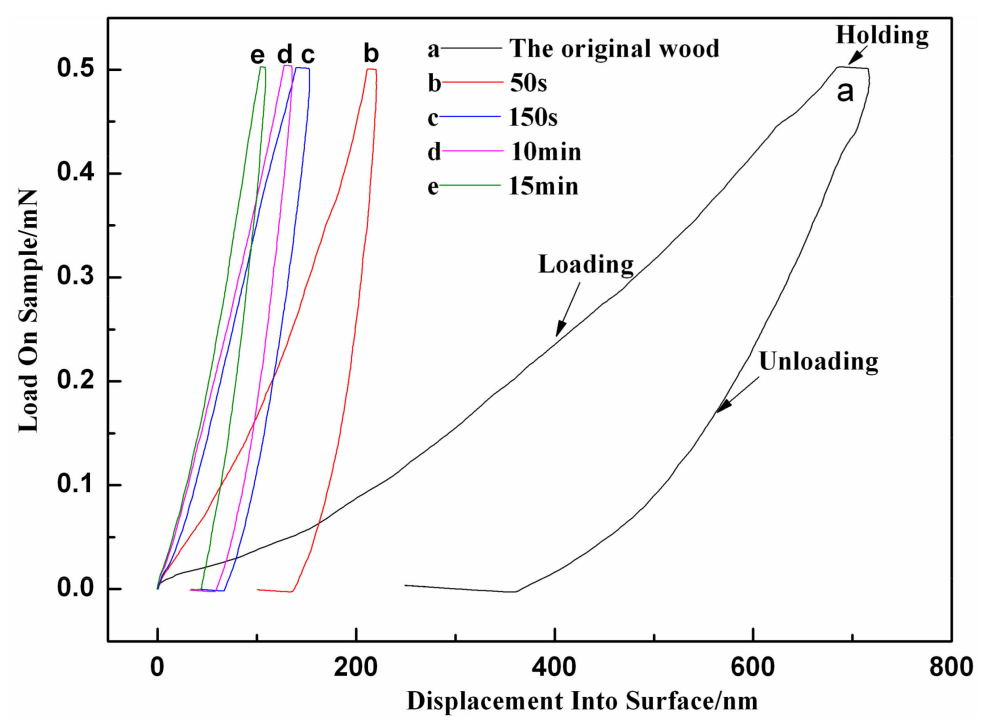

Figure 2. The load-compaction depth curve of wood veneer metallization.

\subsection{Effect of Wood Veneer Metallization on Modulus of Elasticity and Hardness}

The change in the modulus of elasticity of the metallized wood veneer is shown in Figure 3: the modulus of elasticity of wood veneer metallization increases rapidly after metallization, and then growth tends to slow approximately linearly. The average modulus of elasticity of untreated wood is $0.57 \mathrm{GPa}$, and for $50 \mathrm{~s}$ coating was $8.81 \mathrm{GPa}$, which increased by 14.5 times; $9.48 \mathrm{GPa}$ for $150 \mathrm{~s}$, by 15.7 times; $11.7 \mathrm{GPa}$ for $10 \mathrm{~min}$, by 19.6 times; and $14.26 \mathrm{GPa}$ for $15 \mathrm{~min}$, by 24.1 times. As the modulus of elasticity of copper is much larger than that of wood, the growth of the copper film on the surface of wood veneer rapidly increased the modulus of elasticity of wood veneer.

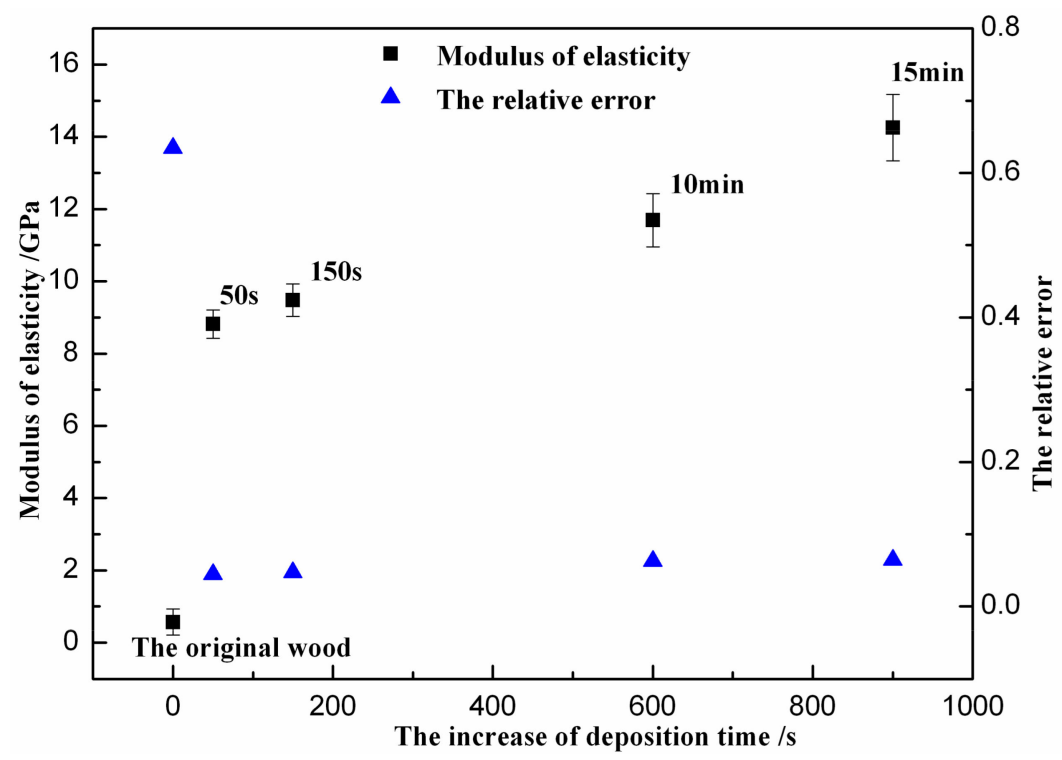

Figure 3. Elastic modulus and corresponding relative error of the metallized wood veneer.

The change in hardness of the metallized wood veneer is shown in Figure 4. After metallization, the hardness of the wood veneer first increased rapidly and then tended to be slow. The average hardness of untreated raw wood was $0.0484 \mathrm{GPa}$, and of $50 \mathrm{~s}$ metallization was $0.3346 \mathrm{GPa}$, which increased by 6.0 times; $0.5654 \mathrm{GPa}$ for $150 \mathrm{~s}$, by 10.8 times; $0.6674 \mathrm{GPa}$ for $10 \mathrm{~min}$, by 12.9 times; and $0.8796 \mathrm{GPa}$ for $15 \mathrm{~min}$, by 17.3 times. As the hardness of copper is much larger than that of wood, the growth of the copper film on the surface of the wood veneer rapidly increased the hardness 
of wood veneer. With the increase of deposition time, the thickness of the copper film increased and the base effect of the wood veneer decreased. The hardness of the sample tends to the hardness of the copper sample itself.

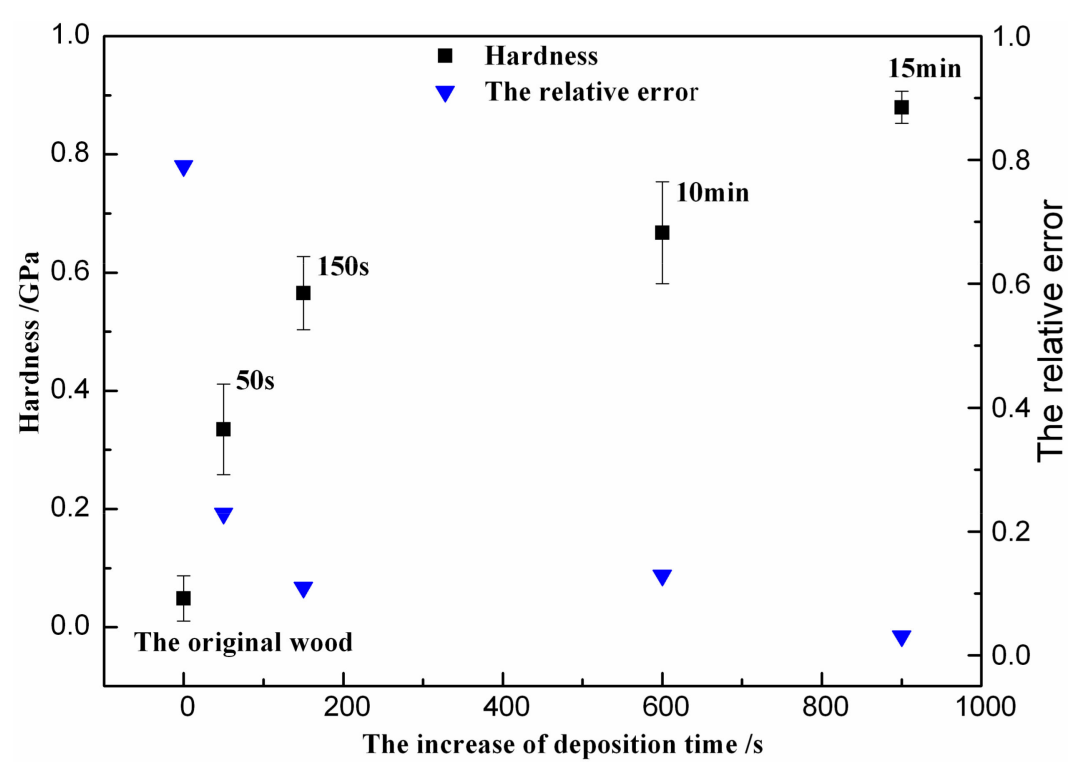

Figure 4. Hardness and corresponding relative error of the metallized wood veneer.

The results show that the relative error of the elastic modulus or hardness of untreated wood is large while that of the metallized wood veneers is small. Since wood is a porous material, the surface is rough and uneven resulting in a large relative error in measuring the elastic modulus and hardness of the untreated wood. In contrast, the copper thin film grown on the wood veneer surface improves the porous structure of wood surface, so that the relative error is reduced. However, since the elastic modulus and hardness of the metallized wood veneer are much larger than those of the untreated wood, relatively large error bars will be displayed in Figures 3 and 4 even if the relative error of elastic modulus and hardness of the metallized wood veneer is small.

\subsection{Microstructure of Metallized Wood Veneer}

Wood veneer metallization scanning electron microscopy (SEM) is shown in Figure 5. The untreated original wood has complex structure, with pores, fibers, parenchyma cells, catheters, wood rays, perforated plates, and so on clearly visible. The surface of the wood veneer becomes flat and smooth after closed treatment, which is favorable to the growth of sputtering copper films. Due to the short sputtering time of $50 \mathrm{~s}$, the sputtering copper atoms gathered and grew on the surface of wood veneer. The surface of the sample with sputtering time of $150 \mathrm{~s}$ formed the island and network structure of the initial film. The samples with sputtering time of $10 \mathrm{~min}$ and $15 \mathrm{~min}$ formed continuous copper thin films on the wood veneer surface. It can be seen that with the increase of deposition time, the sputtering copper atoms gradually nucleate and grow on the surface of the wood veneer; the film growth process is composed of three typical stages, from island to network to continuous film formation. 


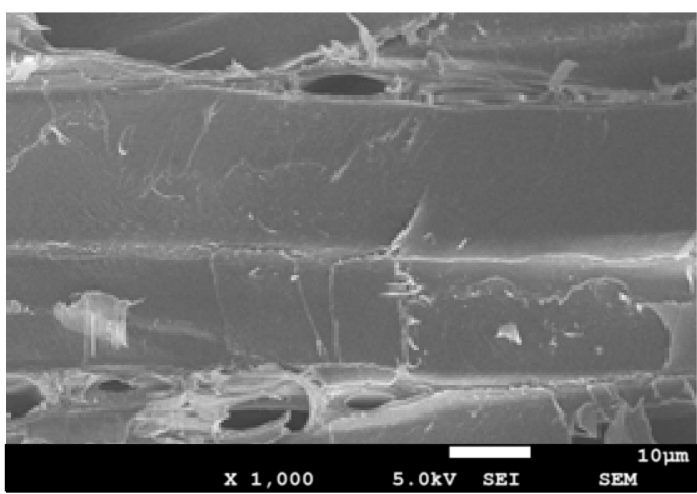

(a)

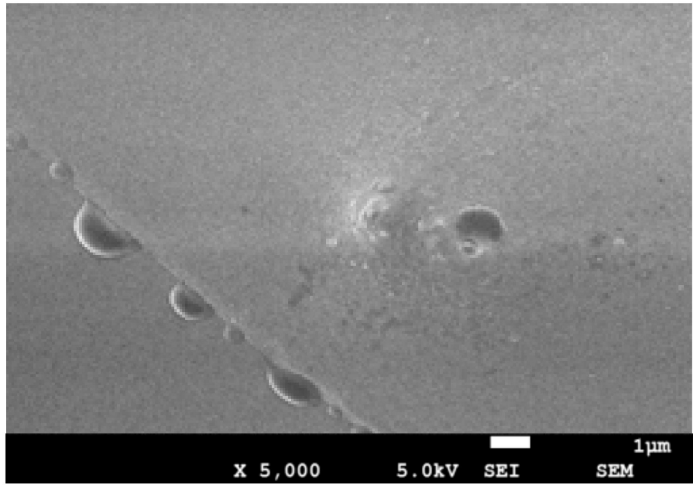

(c)

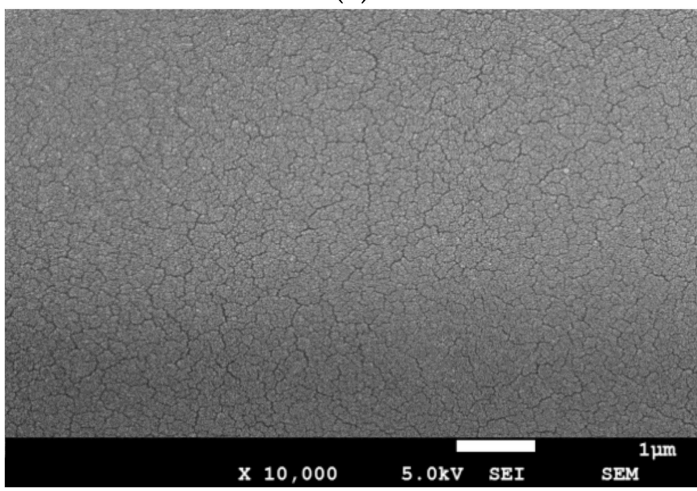

(e)

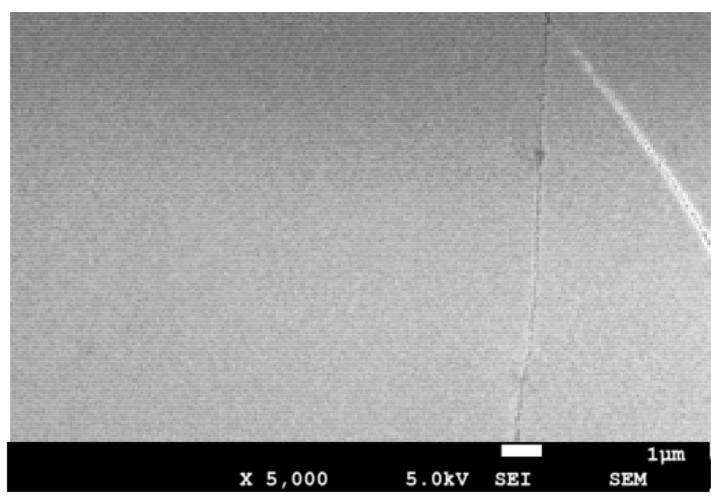

(b)

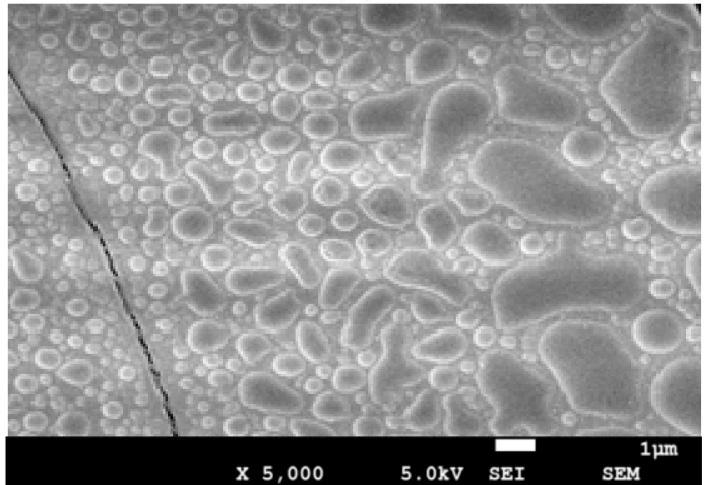

(d)

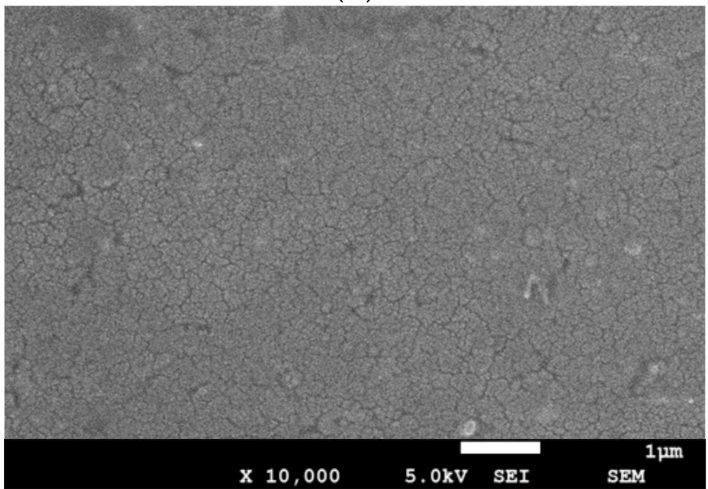

(f)

Figure 5. Metallized wood veneer scanning electron microscopy (SEM): (a) The original wood; (b) wood with sealed processing; (c) magnetron sputtering for $50 \mathrm{~s}$; (d) magnetron sputtering for $150 \mathrm{~s}$; (e) magnetron sputtering for $10 \mathrm{~min}$; and (f) magnetron sputtering for $15 \mathrm{~min}$.

\subsection{Microscale Measurements of Metallized Wood Veneer}

The metallization of wood veneer was achieved by magnetron sputtering. Under different conditions of magnetron sputtering, the microscale parameters of thin film are shown in Table 1. Microscale measurement data such as relative crystallinity, loading displacement, average modulus of elasticity, and average hardness of cellulose of metallized wood veneer under different conditions of sputtering could be obtained. The metallization of wood veneer had a great influence on the relative crystallinity, loading displacement, modulus of elasticity, and hardness of the sample.

The wood is a porous material, so its fiber structure is loose and its surface is rough. The copper film is grown on the surface of the wood, and the copper layer can diffuse into the surface layer of the wood. Therefore, the thickness of the copper film is relative. The thickness of copper film can be obtained by measuring the square resistance of the wood veneer surface. 
The thickness of the copper film $d$ is:

$$
d=\rho / R
$$

where $d$ is the thickness of the copper film, $\rho$ is the resistivity of the film, and $R$ is the square resistance. The samples with sputtering time of $50 \mathrm{~s}$ and $150 \mathrm{~s}$ did not form continuous copper thin films on the wood veneer surface, so it is difficult to define the thickness of the copper films. The thickness of the copper films on the surface of the wood veneer with sputtering time of $10 \mathrm{~min}$ and $15 \mathrm{~min}$ are about $38 \mathrm{~nm}$ and $67 \mathrm{~nm}$, respectively, without considering diffusion into the surface layer of the wood.

Wood veneer metallization by magnetron sputtering improves the mechanical properties of wood veneer, and can meet the needs of wood hardening, mildew resistance, and flame resistance. Moreover, the metallized wood veneer also has the electric conductivity and electromagnetic shielding properties, extending the applications of wood. The copper film grown on the wood surface can completely cover the surface of $\mathrm{MF}_{2}$ blocking agent, which can effectively reduce the release of the $\mathrm{MF}_{2}$ blocking agent. Therefore, the magnetron sputtering method is relatively safe and environmentally friendly for wood metallization. At present, we are also exploring new methods to make the wood surface smooth in order to completely eliminate the use of a $\mathrm{MF}_{2}$ blocking agent.

Table 1. Magnetron sputtering time and microscale parameters of wood veneer metallization.

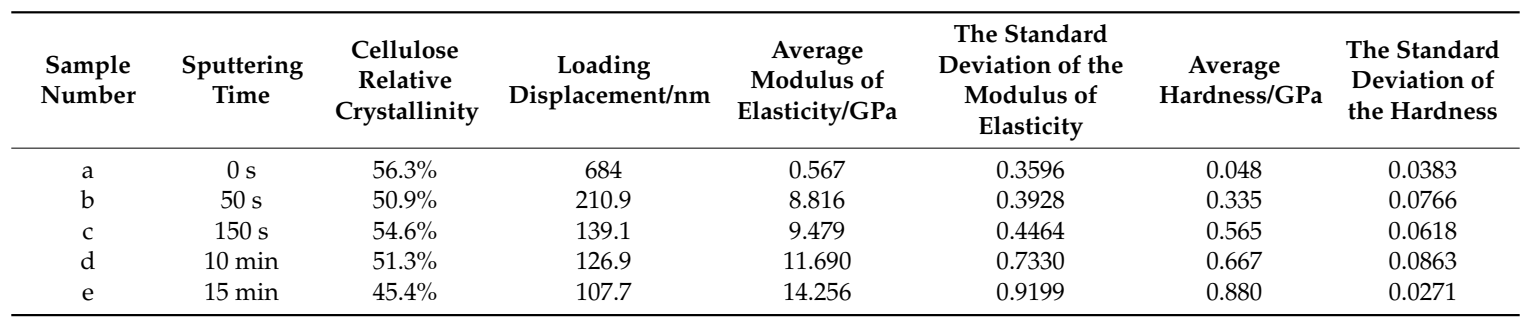

\section{Conclusions}

In this paper, the 31-year-old Pinus sylvestris var. mongolica veneer is used as the substrate to realize the metallization of wood veneer by magnetron sputtering, which makes a surface modification of the wood and changes its microstructure. The metallization structure of wood veneers is characterized by XRD technique. The mechanical properties of surface hardness and elastic modulus of wood veneers after coating were studied by nanoindentation technique. The structure and mechanics of metallized film on wood veneer surface were revealed. The change of properties was observed, and the micromorphological changes of the surface of the magnetron-plated copper-plated wood veneer were tested by SEM. The preparation method of the metallized film on the wood surface and the gradual process of its structure and mechanical properties were explored. The main conclusions are as follows.

(1) Magnetron sputtering can realize wood veneer surface metallization. The gradual process of the metallization structures and mechanical properties of wood veneer were explored, and the XRD analysis results show that the wood veneer metallization has no effect on the crystalline region: the wood cellulose crystalline structure is not destroyed. However, with the increase of deposition time, the characteristic diffraction peak of wood cellulose still exists, strength gradually decreases, the wood cellulose relative crystallinity decreased, and the characteristics diffraction peak of copper occurs, at the same time, the diffraction peaks of $\mathrm{Cu}(111), \mathrm{Cu}(200)$, and $\mathrm{Cu}(220)$ of metallic copper appears, and the intensity of the diffraction peak gradually increases with the increase of coating time. The wood veneer with sputtering time of $15 \mathrm{~min}$ has a good crystallization state of copper film. The metallization scanning electron microscopy (SEM) of the veneer shows that the sputtering copper atoms gradually nucleate and grow on the surface of the veneer and then grow the thin films in three typical stages, from island to network to continuous film formation. 
(2) The mechanical properties of the metallized wood veneer were studied by nanoindentation. Test results showed that the load-compaction depth curve of the metallized sample with sputtering was significantly shifted to the left, the sample with sputtering time of $50 \mathrm{~s}$ was the smallest and the sample with sputtering time of $15 \mathrm{~min}$ was the largest. The loading displacement of the metallized wood veneer decreased significantly. The loading displacement decreased by $80 \%$.

(3) The modulus of elasticity and hardness of wood veneer metallized samples increased by 24.1 times and 17.3 times for the samples whose coating time was $15 \mathrm{~min}$. The modulus of elasticity and hardness of copper are much larger than that of wood. The growth of copper film on the surface of wood veneer rapidly increases the modulus of elasticity and hardness of the wood veneer. As the deposition time increases, the thickness of copper film increases and the base effect of wood gradually decreases.

(4) From the results of SEM measurement of the metallization of wood veneer, it can be seen that the deposited copper atoms gradually nucleate on the wood veneer surface and grow, and the film growth goes through three typical stages, from island to network and then to continuous film formation. Using the magnetron sputtering method, the veneer of Pinus sylvestris var. mongolica can be completely covered by the metal layer of copper film, and the surface of wood veneer can be metallized, which not only preserves the texture of wood itself, but also has the characteristics of metal; the uniform and continuous copper film can be formed on the wood veneer surface.

(5) The magnetron sputtering method is used to prepare metal copper films on the surface of wood veneer, which causes rapid change to the structural and mechanical properties of the wood surface, this expands the practical application of wood and provides new ideas and means for the functional improvement of wood. It also provides technical support for the technological advancement and upgrading of the timber industry, the development of high value-added products, and opens up the application prospect of the functional modification of wood surface.

(6) The preparation of copper thin films on the wood veneer surface with magnetron sputtering to realize the modification of wood interface and the change of wood microstructure can not only maintain the natural characteristics of wood itself, but also enable wood to have a metal crystal structure and mechanical properties, which can realize the improvement of the functional performance of wood. One of the important ways to expand the application of wood is to apply a metal film to the surface of wood, and the metallization of wood veneer is of great significance to the wider application of wood and the increase of its added value.

Author Contributions: The authors have worked together to complete this research.

Funding: The funding for this research was supported by the Fundamental Research Funds for the Central Universities [DL11BB19] and the project of National Science Foundation of China [31570712].

Acknowledgments: The authors would like to thank the editors and the anonymous reviewers for their constructive comments and suggestions, which have helped to improve the paper.

Conflicts of Interest: The authors declare no conflict of interest.

\section{References}

1. Li, J.; Duan, X.F.; Liu, Y.X. Surface modification of wood. J. Northeast For. Univ. 1995, 23, 95-101.

2. Nagasawa, C; Umehara, H; Koshizaki, N. Effects of wood species on electroconductivity and electromagnetic shielding properties of electrolessly plated sliced veneer with nickel. J. Wood Sci. 1994, 40, 1092-1099.

3. Qin, J.; Zhao, G.J.; Shang, J.B.; Pang, J.Y. Electroconductivity and electromagnetic shielding effect of copper plating poplar veneers. J. Beijing For. Univ. 2014, 36, 149-153.

4. Huang, J.T.; Zhao, G.J. Electroless plating of wood. J. Beijing For. Univ. 2004, 26, 88-92.

5. Sun, L.; Li, J.; Wang, L. Electromagnetic interference shielding material from electroless copper plating on birch veneer. Wood Sci. Technol. 2012, 46, 1061-1071. [CrossRef]

6. Wang, L.; Shi, C.; Wang, L. Fabrication of magnetic and EMI shielding wood-based composite by electroless Ni-Fe-P Plating Process. Bioresources 2015, 10, 1869-1878. [CrossRef] 
7. Jia, J.; Cao, S.L.; Wang, Z.J.; Shen, Y.; Wang, P.; Huang, J.T. Research on stability of copper plating solution treated by different reducing agent on wood. J. Inn. Mong. Agric. Univ. 2011, 32, 263-266.

8. Qin, J.; Zhang, M.M.; Zhao, G.J.; Yang, Z. Characterization of wood surface treated with electroless copper plating by near infrared spectroscopy technology. Spectrosc. Spectr. Anal. 2015, 35, 1253.

9. Sun, L.L. Study on the Preparation of Wood-Based Electromagnetic Shielding Material via Novel Electroless Plating Methods. Ph.D. Thesis, Northeast Forestry University, Harbin, China, 2013.

10. Peng, J.; Chen, G.Q.; Song, Y.C.; Gu, K.M.; Tang, J.N. Study on electrical performance of metal copper films deposited by magnetron sputtering on polyimide fiexible substrates. Acta Phys. Sin. 2014, 63, 395-400.

11. Chang, D.L.; Qiu, T.Y.; Wang, Q.Y.; Huang, W.H.; Hu, W.H.; Zhang, Y.L.; Li, Y. Experiment on sputtering metal thin film on wood surface. J. Northeast For. Univ. 2007, 35, 34-36.

12. Guo, D.Z.; Lin, X.; Zhao, Y.Q.; Cao, Y.Q. Application of nanoindentation in the research of materials. Mater. Rev. 2011, 25, 10-14.

13. Yang, H.B.; Hu, M.; Zhang, W.; Zhang, X.-R.; Li, D.J.; Wang, M.-X. Nanoindentation investigation of the hardness and Young'smodulusof porous silicon depending on microstructure. Acta Phys. Sin. 2007, $56,4032-4038$.

14. Wang, C.G.; Jiang, Z.H.; Fei, B.H.; Yu, Y.; Zhang, S.Y. Effects of chemical components on longitudinal MOE and hardness of wood cell wall. J. Beijing For. Univ. 2012, 34, 107-110.

15. Rho, J.Y.; Pharr, G.M. Effects of drying on the mechanical properties of bovine femur measured by nanoindentation. J. Mater. Sci.-Mater. Med. 1999, 10, 485-488. [CrossRef] [PubMed]

16. Sadat, M.R.; Bringuier, S.; Muralidharan, K.; Frantziskonis, G.; Zhang, L. Atomic-scale dynamics and mechanical response of geopolymer binder under nanoindentation. Comput. Mater. Sci. 2018, 142, 227-236. [CrossRef]

17. Fahim, I.S.; Aboulkhair, N.; Everitt, N.M. Nanoindentation investigation on chitosan thin films with different types of nano fillers. J. Mater. Sci. Res. 2018, 7, 11. [CrossRef]

18. Gindl, W.; Gupta, H.S.; Schöberl, T.; Lichtenegger, H.C.; Fratzl, P. Mechanical properties of spruce wood cell walls by nanoindentation. Appl. Phys. A 2004, 79, 2069-2073. [CrossRef]

19. Gindl, W.; Schöberl, T. The significance of the elastic modulus of wood cell walls obtained from nanoindentation measurements. Compos. Part A 2004, 35, 1345-1349. [CrossRef]

20. Jiang, Z.H.; Yu, Y.; Fei, B.H.; Ren, H.Q.; Zhang, T.H. Using nanoindentation technique to determine the longitudinal elastic modulus and hardness of tracheids secondary wall. Sci. Silvae Sin. 2004, 40, 113-118.

21. Oliver, W.C.; Pharr, G.M. An improved technique for determining hardness and elastic modulus using load and displacement sensing indentation experiments. J. Mater. Res. 1992, 7, 1564-1583. [CrossRef]

22. Segal, L.; Creely, J.J., Jr.; Martin, A.E.; Conrad, C.M. An empirical method for estimating the degree of crystallinity of native cellulose using the X-Ray diffractometer. Text. Res. J. 1959, 29, 768-794. [CrossRef]

23. Mwaikambo, L.Y.; Ansell, M.P. Chemical modification of hemp, sisal, jute, and kapok fibers by alkalization. J. Appl. Polym. Sci. 2002, 84, 2222-2234. [CrossRef]

24. Zhang, P.P.; Tong, D.S.; Lin, C.X.; Yang, H.M.; Zhong, Z.K.; Yu, W.H.; Wang, H.; Zhou, C.Z. Effects of acid treatments on bamboo cellulose nanocrystals. Asia-Pac. J. Chem. Eng. 2015, 9, 686-695. [CrossRef]

25. Lv, W.H.; Zhao, G.J. Structure and characterization of Cunninghamia lanceolate wood-MMT inter-calation nanocomposite (WMNC). J. Beijing For. Univ. 2007, 29, 131-135.

(C) 2018 by the authors. Licensee MDPI, Basel, Switzerland. This article is an open access article distributed under the terms and conditions of the Creative Commons Attribution (CC BY) license (http://creativecommons.org/licenses/by/4.0/). 